\title{
Social efficiency benchmarking of transport infrastructure with non-radial approach: focusing on airports
}

\author{
Hun-Koo Ha*, Young-In Jeon**, and Kyung-Chang Min***
}

\begin{abstract}
The aim of this paper is to show current position of domestic airports and provide an improvement scheme through the comparative analysis of efficiency and social efficiency. We used SBM (Slack Based Measure) for efficiency and undesirable output model that is extended from SBM for social efficiency. In addition, window analysis is used for analyzing the trend of the values. For the scope of this study, we analyzed fourteen airports in Korea from 2004 to 2009. In the models, we considered the length of runway, the number of employees and terminal area as input factors, and the number of passengers, the amount of cargo and the number of flights as desirable outputs and directly controllable CO2 emissions from airports as undesirable output. The results show that all of the efficiencies are higher than the social efficiencies and both of them are decreasing by years. To improve social efficiency in 2009, the average amounts of reduced CO2 emissions which account for $48.3 \%$ of the total emissions are required.
\end{abstract}

Keywords: Social efficiency; Undesirable output model; Non-radial approach; Airports

Submission Date: 5/21/2011 Revision Date: 7/15/2011 Acceptance Date: 7/15/2011

* Corresponding Author, Professor, Asia-Pacific School of Logistics, Inha University, email : hkha@inha.ac.kr

** Graduate School of Logistics, Inha University, email : insstory@gmail.com

*** Graduate School of Logistics, Inha University, email : bluebearmin@nate.com 


\section{Introduction}

As the environmental concerns about global warming spread across the world, government of each countries is introducing the concept of sustainability. And they have promoted environmentally sustainable economic growth started from public organizations. In 1997, the Kyoto Protocol set six GHGs (Greenhouse Gas: $\mathrm{CO}_{2}, \mathrm{CH}_{4}, \mathrm{~N}_{2} \mathrm{O}, \mathrm{HFC}_{\mathrm{S}}, \mathrm{PFC}_{\mathrm{S}}$, $\mathrm{SH}_{6}$ ). Among them, $\mathrm{CO}_{2}$ emissions have the highest level of contribution in greenhouse effect (IPCC: Inter-governmental Panel on Climate, 2007). Therefore in this paper, $\mathrm{CO}_{2}$ emissions are considered as environmentally undesirable output factor and assess the level of eco-friendly management of airports through comparison between efficiencies without environmental factor and social efficiencies including environmental factors.

There are fifteen airports that are operating in Korea. But Muan international airport (MWX) was excepted from the analysis because of data limitation. Therefore, the fourteen airports are selected for the object of the analysis. From 2004, airports' operators have calculated the amount of GHGs emissions and they published environmental reports annually such as carbon management reports or sustainable management reports. Based on the published data on their reports from 2004 to 2009, we analyze the efficiency through SBM (Slack Based Measure) which is the Non-radial measurement of efficiency, and extend the SBM to undesirable output model to measure the social efficiency. ${ }^{1)}$ To measure the trend of the efficiency scores, we adopt window analysis which is introduced by Charnes et al. (1985).

\section{Literature Review}

The researches on the efficiency measurements with undesirable outputs have been developed by various approaches. However, there are only a few researches on the efficiency analysis with undesirable outputs for the airports. Pathomsiri et al. (2006) measured the efficiency of the 56 airports in U.S and considered number of delayed flights and delaying time as undesirable outputs. With the methodology, they used DEA (Data Envelopment Analysis) and DDF (Directional Distance Function). Yu et al. (2007) analyzed the efficiency of the four airports in Taiwan and considered noise from aircrafts as undesirable outputs with the MPI (Malmquist Productivity Index) and MLPI (Malmquist-Luenberger Productivity Index). Lozano and Gutierrez (2010) measured the efficiency of the 39 airports in Spain by using SBM and considered delayed flights as undesirable outputs. However, there is no papers which attempt to analyze airports'

1) Social efficiency, eco-efficiency and environmental efficiency have the same meaning. In this paper, we will use social efficiency. 
efficiencies with $\mathrm{CO}_{2}$ emissions as undesirable output. We measured the social efficiency of airports considering the $\mathrm{CO}_{2}$ emissions which are major factors of the greenhouse effects as undesirable output.

\section{Methodology}

SBM is a methodology of measuring efficiency with non-radial approach and introduced firstly by Tone (2001). In the DEA(Data Envelope Approach) which is a radial approach and recently usually used to analyze the efficiency, each DMUs (Decision Making Unit)' relative efficiency is measured by concept of distance in SBM. However, SBM is able to exactly measure efficiency than radial approach such as DEA through the analysis based on slacks that are ignored during the process of measurement.

Assumed that there are n DMUs and let $x_{i j}$ and $y_{i j}$ to denote the amount of input $i$ of airport $j$ and the amount of output $i$ of airport $j$ with $j=1,2, \ldots, n$. The metrics of them are denoted as $X$ and $Y$ and defined as $X=\left(x_{i j}\right) \in R^{m \times n}, Y=\left(y_{i j}\right) \in R^{s \times n}$ and $X>0, Y>0$. The production possibility set is described as follow:

$$
P=\{(x, y) \mid x \geq X \lambda, y \leq Y \lambda, \lambda \geq 0\}
$$

where $\lambda$ is the non-negative intensity vector, and an expression for describing a $\operatorname{DMU}\left(x_{0}, y_{0}\right)$ as follow:

$$
\begin{aligned}
& x_{0}=X \lambda+s^{-}, \\
& y_{0}=Y \lambda-s^{+},
\end{aligned}
$$

$s^{-}$is slack of input and represents excess of input. $s^{+}$is slack of output and represents shortage of output. Tone (2011)'s SBM model is formulated as follow:

$$
\begin{array}{ll}
\text { Minimize } \quad \rho=\frac{1-\left(\frac{1}{m}\right) \sum_{i=1}^{m} \frac{s_{i}^{-}}{x_{i 0}}}{1+\left(\frac{1}{s}\right) \sum_{r=1}^{s} \frac{s_{r}^{+}}{y_{r 0}}} \\
\text { s.t. } \quad x_{0}=X \lambda+s^{-}, \\
& y_{0}=Y \lambda-s^{+}, \\
\lambda \geq 0, s^{-} \geq 0, s^{+} \geq 0 .
\end{array}
$$


Denominator of the objective function is the ratio of average efficiency improvement in input. It means that the ratio represents average amount of decreased $m$ inputs. Numerator of the function is the ratio of average efficiency improvement in output. And it corresponds to average amount of increased $s$ outputs. Therefore, minimizing $\rho$ makes the efficiency increased by the improvement of inputs and outputs at the same time. The constraints limit each DMUs that does not exist out of the production frontier.

To consider undesirable factors, undesirable output model is extended from SBM and introduced by Tone (2001). The model decomposes the matrix of output into $Y^{g}$ and $Y^{b} . Y^{g}$ is good and desirable output matrix and $Y^{b}$ is bad and undesirable output matrix. The production possibility set based on the decomposition of output is described as follow:

$$
P=\left\{(x, y) \mid x \geq X \lambda, y^{g} \leq Y^{g} \lambda, y^{b} \geq Y^{b} \lambda, \lambda \geq 0\right\},
$$

Tone (2011)'s undesirable output model is modified as follow:

$$
\begin{array}{ll}
\text { Minimize } \quad \rho^{*}= & \frac{1-\left(\frac{1}{m}\right) \sum_{i=1}^{m} \frac{s_{i 0}^{-}}{x_{i 0}}}{1+\left(\frac{1}{s_{1}+s_{2}}\right)\left(w_{1} \sum_{r=1}^{s_{1}} \frac{s_{r}^{g}}{y_{r 0}^{g}}+w_{2} \sum_{r=1}^{s_{2}} \frac{s_{r}^{b}}{y_{r 0}^{b}}\right)} \\
\text { s.t. } \quad x_{0}=X \lambda+s^{-}, \\
y_{0}^{g}=Y \lambda-s^{g}, \\
y_{0}^{b}=Y \lambda+s^{b}, \\
\lambda \geq 0, s^{-} \geq 0, s^{g} \geq 0, s^{b} \geq 0 .
\end{array}
$$

where $w$ is the degree with emphasis on desirable and undesirable output. The $\operatorname{DMU}\left(x_{0}, y_{0}^{g}, y_{0}^{b}\right)$ is efficient that considered undesirable output only if $\rho^{*}=1, s^{-}=0, s^{g}=0, s^{b}=0$. If the DMU is inefficient, $\rho^{*}<1$. 


\section{Empirical Result}

\subsection{The data}

In this paper, we considered the length of runway (in meter), the number of employees and terminal area (in square meter) as input factors, and the number of passengers, the amount of cargo (in tons) and the number of flights as desirable outputs and the amount of $\mathrm{CO}_{2}$ emissions (in ton of $\mathrm{CO}_{2}$ ) which is directly controllable by airport operators as undesirable output. $\mathrm{CO}_{2}$ emissions data are shown on Green report and Carbon management report published by IIAC (Incheon International Airport Corporation) and KAC (Korea Airports Corporation). Emissions factors and GWP (Global Warming Potential) in 2006 IPCC guidelines for national Greenhouse Gas Inventories were adopted to calculate $\mathrm{CO}_{2}$ emissions and for the third party verification, verified by KEMCO (Korean Energy Management Corporation) GHG certification office. The scope of the directly control includes $\mathrm{CO}_{2}$ emissions from passenger terminal, boarding building and traffic center as sector of passengers and air-side facility and land-side facility as sector of airport operation. Aircraft emissions and emissions from commercial facilities are not included in the data. In case of $\mathrm{CO}_{2}$ emissions in airports, $\mathrm{CO}_{2}$ emissions from aircrafts movements occupy over half of the total $\mathrm{CO}_{2}$ emissions. However it is difficult to calculate exactly the amount, and besides, not only airlines but also aircraft manufacturers are responsible for the emissions. Therefore, we considered only directly controllable emissions by the airport operators.

Table 1.

Correlation between inputs, desirable outputs and undesirable outputs

\begin{tabular}{c|c|c|c|c|c|c|c}
\hline \multirow{2}{*}{ Year } & \multicolumn{7}{|c}{$\mathbf{C O}_{\mathbf{2}}$ emissions } \\
\cline { 2 - 8 } & $\mathbf{2 0 0 4}$ & $\mathbf{2 0 0 5}$ & $\mathbf{2 0 0 6}$ & $\mathbf{2 0 0 7}$ & $\mathbf{2 0 0 8}$ & $\mathbf{2 0 0 9}$ & Avg. \\
\hline Runway length & 0.582 & 0.596 & 0.591 & 0.550 & 0.805 & 0.808 & 0.655 \\
\hline Terminal area & 0.992 & 0.989 & 0.989 & 0.988 & 0.995 & 0.996 & 0.991 \\
\hline \# of employee & 0.822 & 0.842 & 0.846 & 0.852 & 0.833 & 0.826 & 0.837 \\
\hline Passengers & 0.890 & 0.920 & 0.925 & 0.938 & 0.912 & 0.890 & 0.913 \\
\hline Cargo & 0.986 & 0.983 & 0.983 & 0.987 & 0.993 & 0.994 & 0.988 \\
\hline \# of flights & 0.862 & 0.902 & 0.919 & 0.921 & 0.872 & 0.872 & 0.895 \\
\hline
\end{tabular}

Table 2 provides statistics of 14 airports samples from 2004 to 2009. In the Table 2, it shows that average $\mathrm{CO}_{2}$ emissions of 14 airports are slightly decreased in 2009 after increasing from 2004 to 2008. Table 1 reports on the correlation between factors and $\mathrm{CO}_{2}$ 
emissions. As seen in Table 1, terminal area and cargo are highly related with $\mathrm{CO}_{2}$ emissions. The runway length, on the other hand, has the lowest correlation with $\mathrm{CO}_{2}$ emissions.

Table 2.

Descriptive statistics of the airport samples, 2004-2009

\begin{tabular}{|c|c|c|c|c|c|c|c|c|c|c|c|c|c|}
\hline \multirow{2}{*}{ Year } & \multicolumn{2}{|c|}{2004} & \multicolumn{2}{|c|}{2005} & \multicolumn{2}{|c|}{2006} & \multicolumn{2}{|c|}{2007} & \multicolumn{2}{|c|}{2008} & \multicolumn{3}{|c|}{2009} \\
\hline & Mean & SD & Mean & SD & Mea & SD & Mea & SI & Me: & S & & Mean & SD \\
\hline
\end{tabular}

Inputs

\begin{tabular}{c|c|c|c|c|c|c|c|c|c|c|c|c}
\hline $\begin{array}{c}\text { Runway } \\
\text { length }\end{array}$ & 4,328 & 1,889 & 4,367 & 1,836 & 4,367 & 1,836 & 4,569 & 1,812 & 4,855 & 2,453 & 4,855 & 2,453 \\
\hline $\begin{array}{c}\text { Terminal } \\
\text { area }\end{array}$ & 81,011 & 163,045 & 82,838 & 164,903 & 83,739 & 164,490 & 83,248 & 162,907 & 105,240 & 227,330 & 105,240 & 227,330 \\
\hline $\begin{array}{c}\text { \# of } \\
\text { employee }\end{array}$ & 182 & 256 & 183 & 258 & 181 & 260 & 186 & 267 & 186 & 269 & 183 & 262 \\
\hline
\end{tabular}

\section{Desirable outputs}

\begin{tabular}{c|c|c|c|c|c|c|c|c|c|c|c|c}
\hline Passengers & $4,664,865$ & $7,007,036$ & $4,611,218$ & $7,307,569$ & $4,830,198$ & $7,843,834$ & $5,079,331$ & $8,525,527$ & $4,987,334$ & $8,308,630$ & $5,013,958$ & $8,186,345$ \\
\hline Cargo & 241,928 & 635,158 & 240,094 & 648,111 & 254,570 & 704,820 & 269,351 & 773,782 & 250,337 & 739,812 & 210,005 & 588,881 \\
\hline $\begin{array}{c}\text { \# of } \\
\text { flights }\end{array}$ & 32,616 & 44,779 & 31,532 & 45,905 & 33,373 & 50,765 & 37,071 & 58,576 & 37,680 & 59,489 & 37,587 & 58,082 \\
\hline
\end{tabular}

\section{Undesirable outputs}

\begin{tabular}{c|c|c|c|c|c|c|c|c|c|c|c|c}
\hline $\begin{array}{c}\mathrm{CO}_{2} \\
\text { emissions }\end{array}$ & 10,688 & 24,854 & 11,180 & 25,564 & 11,209 & 25,346 & 11,958 & 27,773 & 13,590 & 34,010 & 13,052 & 32,329 \\
\hline
\end{tabular}

\subsection{Efficiency and social efficiency}

The window analysis is able to verify the stability of the data groups and check whether the efficiencies are stable, deteriorating and improving or not. Therefore, we draw the trend of efficiency through the window analysis after estimation of efficiency and social efficiency. Table 3 shows the efficiency and social efficiency by window analysis and yearly change on average of both efficiencies are expressed in Figure 1.

The result of the efficiency analysis shows that average of technical efficiency is higher than social efficiency in all years. Both of efficiencies are consistently decreasing 


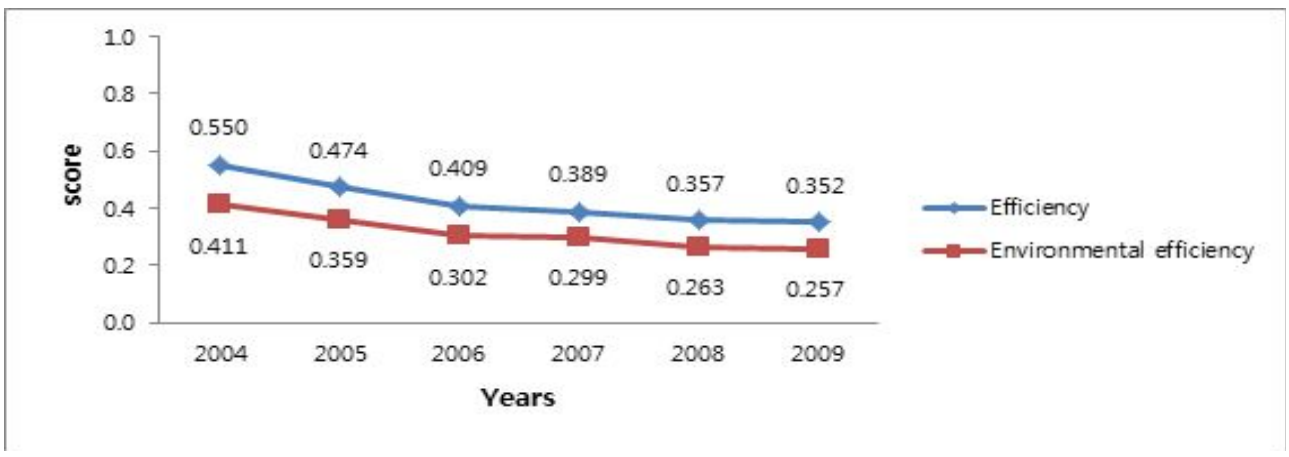

Figure 1.

Average efficiency and social efficiency score by window analysis

and there is no increasing trend. The decline in the efficiency scores from 2004 to 2006 is relatively larger than those of other years and it continues to decrease over time.

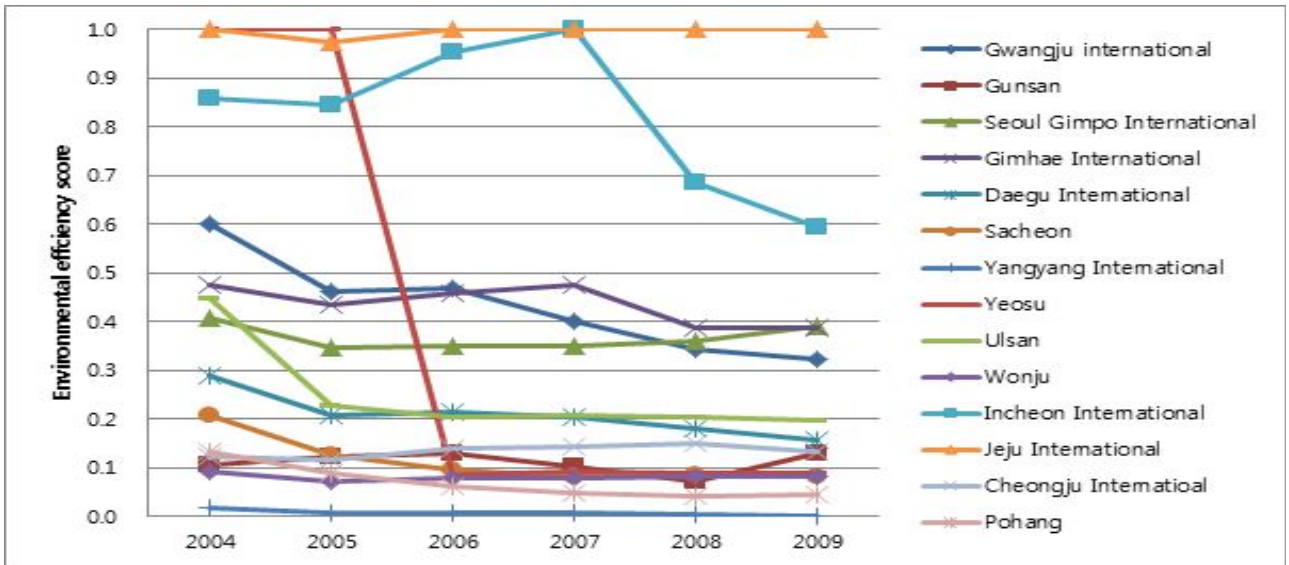

Figure 2. Variation of social efficiency by years

Figure 2 shows the trend of social efficiency in each airports based on Table 3. CJU has a trend of the highest efficiency during the whole sample period. YNY, on the other hand, has a trend of the lowest efficiency. In terms of the variation in social efficiency, most of airports except for RSU and ICN indicates stable efficiency level. The efficiency level of RSU is high from 2004 to 2005, but rapidly decreases from 2005 to 2006 and slightly increases again in 2009. The reason of the RSU's variation is that terminal area was largely extended from $1,517 \mathrm{~m}^{2}$ in 2005 into $14,131 \mathrm{~m}^{2}$ in 2006. and the amount of $\mathrm{CO}_{2}$ emissions were sharply increased from $681 \mathrm{tCO}_{2}$ in 2005 to $2,122 \mathrm{tCO}_{2}$ in 2006. ICN shows an increasing trend from 2005 to 2007 and rapidly decreasing trend from 2007 to 2009 
because it is affected by increasing runway length from $7,500 \mathrm{~m}$ in 2007 to $11,500 \mathrm{~m}$ in 2008 , terminal area from $625,001 \mathrm{~m}^{2}$ in 2007 to $890,000 \mathrm{~m}^{2}$ in 2008 , number of employees from 862 persons in 2007 to 880 persons in 2008 and $\mathrm{CO}_{2}$ emissions from 109, $106 \mathrm{tCO}_{2}$ in 2007 to $134,018 \mathrm{tCO}_{2}$ in 2008. In case of YNY, efficiency score is 0 in 2009 because operation is interrupted by suspension of all regular service from airlines.

Table 3.

Efficiency and social efficiency score by window analysis, 2004-2009

\begin{tabular}{c|c|c|c|c|c|c|c|c|c|c|c|c}
\hline \multirow{2}{*}{ Airport } & \multicolumn{2}{|c|}{2004} & \multicolumn{2}{|c|}{$\mathbf{2 0 0 5}$} & \multicolumn{2}{c|}{$\mathbf{2 0 0 6}$} & \multicolumn{2}{c|}{$\mathbf{2 0 0 7}$} & \multicolumn{2}{|c|}{2008} & \multicolumn{2}{c}{2009} \\
\cline { 2 - 13 } & $\mathbf{E}^{*}$ & $\mathbf{S E}$ & $\mathbf{E}^{*}$ & $\mathbf{S E}$ & $\mathbf{E}^{*}$ & $\mathbf{S E}$ & $\mathbf{E}^{*}$ & $\mathbf{S E}$ & $\mathbf{E}^{*}$ & $\mathbf{S E}$ & $\mathbf{E}^{*}$ & $\mathbf{S E}^{*}$ \\
\hline \hline KWJ & 0.791 & 0.602 & 0.619 & 0.462 & 0.610 & 0.467 & 0.508 & 0.399 & 0.459 & 0.344 & 0.433 & 0.323 \\
\hline KUV & 0.172 & 0.107 & 0.196 & 0.123 & 0.181 & 0.128 & 0.140 & 0.101 & 0.098 & 0.072 & 0.162 & 0.130 \\
\hline GMP & 0.571 & 0.406 & 0.557 & 0.346 & 0.487 & 0.348 & 0.478 & 0.349 & 0.499 & 0.361 & 0.522 & 0.389 \\
\hline PUS & 0.594 & 0.473 & 0.558 & 0.433 & 0.588 & 0.458 & 0.604 & 0.476 & 0.522 & 0.388 & 0.526 & 0.387 \\
\hline TAE & 0.466 & 0.288 & 0.323 & 0.207 & 0.324 & 0.213 & 0.300 & 0.204 & 0.259 & 0.180 & 0.216 & 0.157 \\
\hline HIN & 0.428 & 0.206 & 0.279 & 0.126 & 0.203 & 0.094 & 0.177 & 0.081 & 0.190 & 0.084 & 0.189 & 0.082 \\
\hline YNY & 0.083 & 0.016 & 0.038 & 0.008 & 0.053 & 0.007 & 0.046 & 0.005 & 0.012 & 0.003 & 0.000 & 0.000 \\
\hline RSU & 1.000 & 1.000 & 1.000 & 1.000 & 0.241 & 0.085 & 0.229 & 0.092 & 0.219 & 0.090 & 0.210 & 0.089 \\
\hline USN & 0.855 & 0.446 & 0.580 & 0.227 & 0.504 & 0.204 & 0.449 & 0.207 & 0.453 & 0.204 & 0.432 & 0.197 \\
\hline WJU & 0.219 & 0.092 & 0.156 & 0.072 & 0.161 & 0.078 & 0.152 & 0.078 & 0.153 & 0.081 & 0.150 & 0.080 \\
\hline ICN & 0.914 & 0.858 & 0.892 & 0.845 & 0.954 & 0.952 & 1.000 & 1.000 & 0.766 & 0.685 & 0.694 & 0.593 \\
\hline CJU & 1.000 & 1.000 & 0.986 & 0.975 & 1.000 & 1.000 & 1.000 & 1.000 & 0.982 & 1.000 & 1.000 & 1.000 \\
\hline CJJ & 0.178 & 0.123 & 0.179 & 0.115 & 0.220 & 0.139 & 0.218 & 0.143 & 0.232 & 0.149 & 0.204 & 0.133 \\
\hline KPO & 0.428 & 0.133 & 0.279 & 0.088 & 0.198 & 0.062 & 0.143 & 0.046 & 0.149 & 0.039 & 0.182 & 0.046 \\
\hline AVG. & 0.550 & 0.411 & 0.474 & 0.359 & 0.409 & 0.302 & 0.389 & 0.299 & 0.357 & 0.263 & 0.352 & 0.257 \\
\hline
\end{tabular}

Notes: E: efficiency score, SE: social efficiency score

\subsection{An improvement scheme}

Figure 3 shows the current positions of airports in efficiency level in 2009. The horizontal axis of the graph indicates social efficiency score, and the vertical axis of the graph indicates technical efficiency score. The dotted diagonal line on the graph is a standard which represents the same level of both efficiencies. The airports that have higher technical efficiency compared to social efficiency are located on the left side of the line. On the contrary, if an airport is on the right side of the line, its efficiency level is higher when the environmental factors are considered. Thus the airport is operating in an 
environmentally friendly way when an airport exists on the right side of the line rather than in the left side.

In terms of position of the airports in 2009, all airports except CJU exist on the left side of the line, and besides most of them are at the bottom of the graph. The position means that this is not only undesirable in the environment perspective but also technically inefficient. Thus, they should do efforts to move to the right-hand corner of the graph. CJU which exceptionally exists in the top right-hand corner is an ideal airport because it is efficient in both technical and environmental parts. However, there is a limitation in reporting that CJU is a perfectly ideal and efficient airport because measured efficiency scores are relative efficiency in the sampled airports.

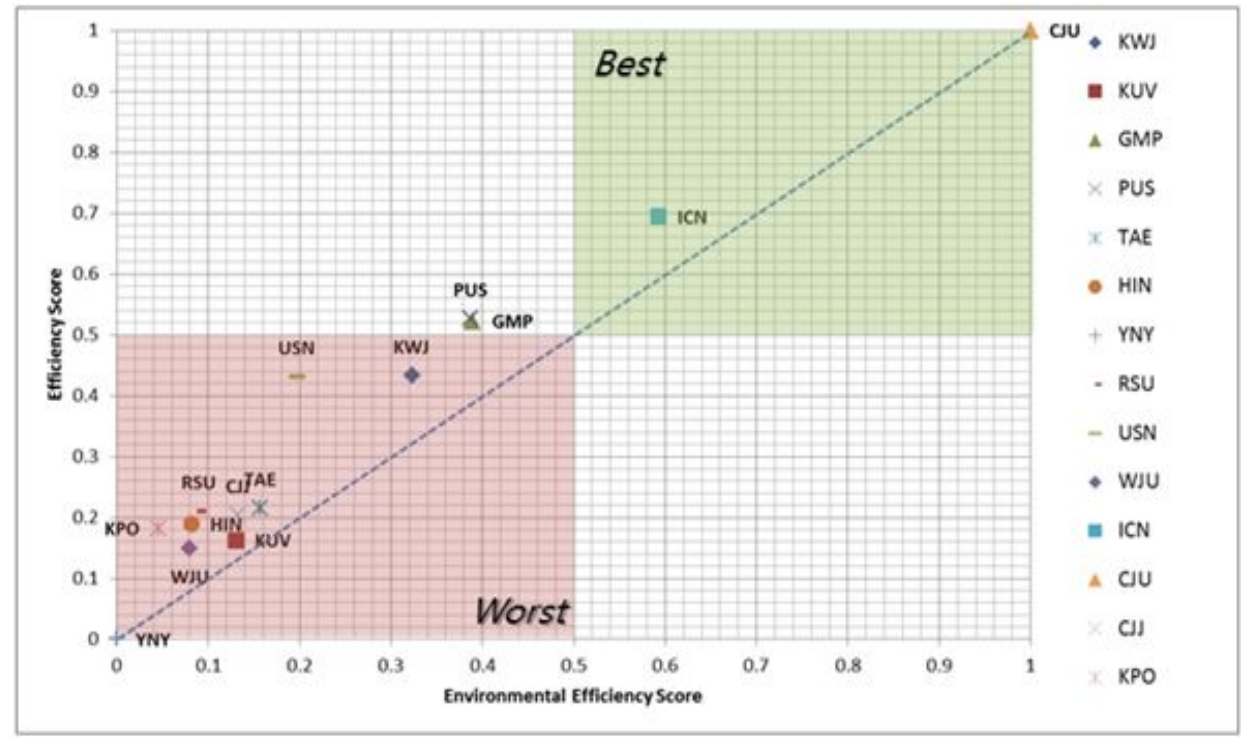

Figure 3.

Current efficiency level and the direction of improvement (2009)

In order to improve the airports' technical and social efficiency, it is necessary to know the quantity of required reduction in input part and the quantity of required increase in output part. Table 4 shows the average percentage change of inputs and outputs required to improve the efficiency to the level of the highest efficient airport. The percentages are calculated as follows:

Percentage of quantity of required improvement $=$

$\frac{\text { Quantity of slacks or inputs or outputs }}{\text { Ordinaryinputs } \text { or outputs }} \times 100$ 
In terms of the required reduction in inputs, percentage of quantity of required improvement is increasing over time in all inputs. The reason is that most of inputs are regarded as superabundant inputs as the efficiencies are decreasing. In case of runway length, $50 \%$ of ordinary quantity should be reduced in 2004 and $70.8 \%$ should be reduced in 2009 , terminal area, $33.4 \%$ in 2004 and $63.1 \%$ in 2009 should be cut, number of employees, $39.5 \%$ in 2004 and $63.1 \%$ in 2009 should be reduced. But practically, it is difficult to reduce runway length and terminal area. Nevertheless, these percentages show that most of airports have relatively huge size than their demand and it provides a lot of implications for the decision process of the size of the airports to be constructed in the future.

Table 4.

Average percentage of inputs and outputs required to improve

\begin{tabular}{|c|c|c|c|c|c|c|c|c|c|c|c|c|}
\hline \multirow{2}{*}{ Year } & \multicolumn{2}{|c|}{2004} & \multicolumn{2}{|c|}{2005} & \multicolumn{2}{|c|}{2006} & \multicolumn{2}{|c|}{2007} & \multicolumn{2}{|c|}{2008} & \multicolumn{2}{|c|}{2009} \\
\hline & Mean & SD & Mean & SD & Mean & SD & Mean & SD & Mean & SD & Mean & SD \\
\hline \multicolumn{13}{|l|}{ Inputs } \\
\hline $\begin{array}{c}\text { Runway } \\
\text { length }\end{array}$ & 50.0 & 43.1 & 58.3 & 39.7 & 67.0 & 35.9 & 70.5 & 36.1 & 70.5 & 36.3 & 70.8 & 36.5 \\
\hline $\begin{array}{c}\text { Terminal } \\
\text { area }\end{array}$ & 33.4 & 29.1 & 39.9 & 31.1 & 45.9 & 28.4 & 43.2 & 28.8 & 50.6 & 28.6 & 54.2 & 28.5 \\
\hline $\begin{array}{c}\text { \# of } \\
\text { employee }\end{array}$ & 39.5 & 32.8 & 47.7 & 31.8 & 55.0 & 30.0 & 60.0 & 30.1 & 61.5 & 30.8 & 63.1 & 30.9 \\
\hline \multicolumn{13}{|c|}{ Desirable outputs } \\
\hline Passengers & 29.6 & 32.8 & 32.1 & 27.5 & 43.7 & 52.5 & 34.1 & 72.1 & 24.0 & 35.0 & 21.8 & 22.4 \\
\hline Cargo & 127.5 & 152.8 & 652.1 & 1291.9 & 1000.7 & 2073.4 & 1115.6 & 2304.7 & 551.2 & 1017.6 & 218.3 & 273.7 \\
\hline $\begin{array}{l}\text { \# of } \\
\text { flights }\end{array}$ & 0.0 & 0.2 & 0.0 & 0.0 & 0.0 & 0.0 & 0.3 & 1.1 & 0.1 & 0.4 & 0.0 & 0.0 \\
\hline \multicolumn{13}{|c|}{ Undesirable outputs } \\
\hline $\begin{array}{c}\mathrm{CO}_{2} \\
\text { emissions }\end{array}$ & 31.1 & 27.8 & 40.5 & 27.8 & 43.7 & 27.8 & 37.6 & 27.3 & 48.5 & 28.2 & 48.3 & 28.5 \\
\hline
\end{tabular}

In terms of the requirement of desirable outputs, percentage of required improvement of passengers is decreasing over time. For the cargo improvements, percentage of requirement is rapidly decreasing after 2007, but it is very much higher than those of any other input factors. This shows that most of the airports, at present, are focusing on passengers. However we could suggest that if their operation strategy is focusing on the improvement of cargo, they can get more efficient performance.

In terms of the undesirable outputs, $\mathrm{CO}_{2}$ emissions are required to be reduced by $31 \%$ of ordinary emissions in 2004 and $48.3 \%$ in 2009 in order to get environmentally efficient airport operation. The number of $48.3 \%$ in the ordinary emissions is large proportion, when we consider the points that the amount of directly controllable emissions by airport 
operators is analyzed in this research. In the overview of airport, if emissions from lessees and aircrafts are added, the quantity of required reduction may be fairly increased. Thus, to reduce the $\mathrm{CO}_{2}$ emissions, it is necessary to adopt the cooperative efforts among the stakeholders, not independent efforts of the airport operators. Furthermore, the effects of the efforts will appear in the long term compared to those of other factors. Therefore, the sustainable long term strategies are required to increase environmental efficiency.

\section{Concluding remarks}

In this paper, airports' efficiencies and social efficiencies are measured by SBM model and undesirable output model with non-radial approach. To know the trend of both efficiencies form 2004 to 2009, 3-years-window analysis is used and the scores of each efficiencies are compared. The efficiency analysis shows that the average of technical efficiency is higher than social efficiency in all the sample period. And both of the efficiencies are consistently decreasing and there is no increasing trend. The decline in efficiency level from 2004 to 2006 is relatively larger than that od other years and it continues to decrease over time. In terms of environmental or social efficiency, CJU is the most efficient airport and YNY is the most inefficient airport. The results of positioning the airports show that most of airports are inefficient and also environmentally inefficient. These airports need to do efforts to improve both efficiency. In terms of the required reduction of undesirable outputs, $\mathrm{CO}_{2}$ emissions should be reduced by $31 \%$ of ordinary emissions in 2004 and by $48.3 \%$ in 2009, in order to get environmentally efficient airport. In the overview of airport, if emissions from lessees and aircrafts are added, the quantity of required reduction may be fairly increased. Thus, to reduce the $\mathrm{CO}_{2}$ emissions, it is necessary to adopt cooperative efforts among the stakeholders, not independent efforts of the airport operators.

This research can be extended in various ways. First, related to the analyzed undesirable factors, it is possible to consider not only $\mathrm{CO}_{2}$ emissions for global warming but also other pollutants for environmental impacts. Second, the social efficiency can be measured more exactly by the other model which can consider in detail the relationship between inputs, outputs and undesirable outputs. Thirdly, in the undesirable output model, measured social efficiency is not pure in the process of measurement. In other words, the social efficiency involves concept of technical efficiency. Thus, it is necessary to work for decomposing the social efficiency into purely environmental effects and technical effects. Finally, if the overall $\mathrm{CO}_{2}$ emissions data from airports are added, the results may be more meaningful. And also, it will be useful to analyze the social efficiency of major airports in the world.

Acknowledgement: This research is supported by LG Yonam Foundation. 


\section{References}

Chin, Anthony T.H. and Joyce M.W. Low. 2010. Port performance in Asia: Does production efficiency imply environmental efficiency?. Transportation Research Part D. 15, 483-488.

Incheon International Airport Corporation. 2009. 2009 Green report.

Incheon International Airport Corporation. 2010. 2010 Green report.

IPCC. 2006. 2006 IPCC Guidelines for National Greenhouse Gas Inventories.

Korea Airports Corporation. 2010. 2010 Carbon management report.

Lozano, S. and Ester Gutierrez. 2009. Efficiency Analysis and target Setting of Spanish Airports. Springer Science+Business Media. 139-15.

Lozano, S. and Ester Gutierrez. 2011. Slack-based measure of efficiency of airports with airplanes delays as undesirable outputs. Computers \& Operations Research. 38: 131-139.

Morita, H. and Koichiro Hirokawa., and Joe Zhu. 2005. A slack-based measure of efficiency in context-dependent data envelopment analysis. Omega. 33: 357-362.

Tone, K. 2001. A slacks-based measure of efficiency in data envelopment analysis. European Journal of Operational Research. 130: 398-509.

Zhang, B., Bi, J., Fan, Z., Yuan, Z., Ge, J. 2008. Eco-efficiency analysis of industrial system in China: A data envelopment approach. Ecological Economics. 68: 306-316.

Zhou, P. and Ang, B.W. 2008. Linear programming models for measuring economy-wide energy efficiency performance. Energy Policy. 36: 2911-2916.

Zhou, P., Ang, B.W. and Poh, K.L. 2006. Slack-based efficiency measures for modeling environmental performance. Ecological Economics. 60: 111-118.

Zhou, P., Poh, K.L. and Ang, B.W. 2007. A non-radial DEA approach to measuring environmental performance. European Journal of Operational Research. 178: $1-9$. 